\title{
Values ethics and legal ethics: the QLD and LETR recommendations 6, 7, 10, and 11
}

Key Words: Ethics; QLD; identity; critical thinking; value; LETR Report

\author{
Graham Ferris
}

Nottingham Law School

Nottingham Trent University

\begin{abstract}
The LETR Report recommended increased attention to ethics and values and to critical thinking. These aims could be achieved jointly through teaching ethical thinking: not as theory but as part of developing the capacity for ethical conduct. Such a pedagogy has the potential to become a QLD signature pedagogy supporting "life-narratives" of students.
\end{abstract}

The LETR Report recommends a review of the QLD emphasising legal values and ethics. Concern with values and ethics is linked to concern with professional conduct. Maintaining the law degree as a general or liberal qualification is also strongly desired. These potentially conflicting drivers generate ambivalence towards legal ethics as a subject for study, especially if legal ethics is perceived as teaching the professional codes.

Resolution of this tension is achievable through recognising the potential role of ethical teaching as part of an identity apprenticeship. Developing ethical character is as much a liberal as a professional aim. Ethics teaching can play an integrative role in the QLD.

Formation of student identity is a central part of Higher Education taking colouration from being situated in legal education. In this context teaching legal ethics becomes the use of a salient example for carrying out the broader project of developing ethical capacity.

\section{Teaching of professional ethics and values for integrity and quality}

The importance of ethics and values within legal education and training is stressed by the final report of the Legal Education and Training Review independent research team (LETR Report). "Ethics" includes professional ethics and "values" those values specifically that underpin the rule of law: these two areas link up with a concern with professionalism. This emphasis on ethics and values is situated within a regulatory context. This means that ethics and values are important when they serve the broader objectives of supporting systemic integrity and service quality, rather than for their own sake. The perspective of the team was informed by the needs of the justice system and the legal services market: the general public, providers, and consumers, as well regulators.

As an educator committed to increasing the role and range of values based teaching and learning in legal education and working in academic higher education my perspective is different. My starting point is that value informed legal education and ethical education is 
beneficial for my students, both those who go on to become legal service providers and those who do not. Even in the context of professional training and continuing professional development a concern with facilitating the growth of the capabilities of the learner to reason and act ethically is my focus.

The Foreword to the LETR Report identifies several "key messages", most of which seem to be broad objectives for legal education and training. Given first place is conservation of the existing strengths of legal education, training and professional practice. However, immediately after conservation is the need to encourage flexibility and responsiveness to changes originating from disparate causal agents. To conserve yet facilitate change: and not merely peripheral change but changes that are likely to touch all aspects of professional practice. At best this is dynamic tension that will give energy and direction to reform efforts, at worst it is contradictory.

The complexity of developments in the UK legal services market is striking. There have been unprecedented advances in information technology. The economic context of legal practice has changed. State subsidy of legal services has been under attack for many years. The conditional fee has generated problems and opportunities. Concurrently "globalisation" has given rise to international competition in legal services. The structure and identity of providers of legal services has also started to change. There is growing diversification of professional providers (the LETR Report was commissioned by ILEX Professional Standards as well as the Bar Standards Board and Solicitors' Regulation Authority) as well as greater specialisation within and between firms; and the possibilities for the structure of business organisations providing legal services has been revolutionised. This diversification, fragmentation, and reorganisation have been driven in part by statutory change and in part by technological and market forces. Finally, but most obviously pertinent to the commissioners of the LETR, changes in regulatory models and structures operating in the market require a response from regulators.

Another key message is a desire to increase diversity in the professions. It seems fair to portray conservation, flexibility, diversity, and regulatory challenges as problems that need addressing: tasks for the professional bodies, regulators, and service providers.

With some resemblance to hope at the bottom of the jar opened by Pandora is the key message of the importance of ethics, or professional ethics and values. Ethical education and training is more in the nature of a remedy for problems identified in other key messages. Although the Foreword identifies work based learning, including continuing professional development, as a possible source of solutions in the future it is as yet very problematic. ${ }^{1}$

\footnotetext{
${ }^{1}$ Although optimistic about work based learning the Report records evidence of substantial dissatisfaction with current Continuing Professional Development (CPD) provision and practice: see LETR Report [2.147] - [2.163]. There are also concerns about the coherence, consistency and effectiveness of traditional work place training, see: [6.61] and [6.63] the crucial factor is the quality of supervision. This means solutions of the problems identified at [6.62] are essential. Supervision is a candidate for prescribed CPD [5.96] - [5.97]. So, if reform of
} 
Also, wider use of outcomes based regulation with alignment of learning and teaching, and assessment, with appropriate outcomes is put forward as a powerful tool for coordination and the achievement of consistency and regulatory purposes. ${ }^{2}$ However, an outcomes defined approach is largely undeveloped outside of the academy, although ILEX has already implemented a learning outcomes approach.

Thus, although the potential importance of new approaches to education and training is recognised these must be considered to be areas that are as yet under development. For example more variety in, more extensive use of, and better focussing of work place learning is potentially important: for facilitating diversity, ensuring competence, and providing a powerful experiential pedagogy.

The use of professional ethics to constrain professional action, to empower the professional in resisting improper pressure, and as a well established feature of professional education and training, marks ethics out. It is familiar and we have experience in its use in educational practice. It is familiar as an aspect of professional practice that is important, useful, and valued. An ethically informed legal education and training can hope to both conserve professional standards and at the same time facilitate beneficial change: for the nature of ethical principles is that they are capable of application in new circumstances. And this should make those committed to teaching in a value informed way that encourages ethical growth a little wary. There is a lot that can be accomplished through the inculcation of values and the facilitation of ethical behaviour - but it cannot be a panacea. Furthermore, there is a tension between ethical education that attempts more than teaching the code and assessment of outcomes based educational practices that must be negotiated very carefully. ${ }^{3}$

\section{Two cheers for the research team}

\footnotetext{
CPD succeeds then it might remedy some problems of supervision in work based learning. Obviously this will need a new and far more rigorous audit process of work based learning [6.71]. All of these integrated parallel reforms are to be co-ordinated through standards expressed as outcomes, and standardised assessment: except for CPD which needs to give more recognition to informal but structured (therefore, not standardised) learning practices [6.95] and [7.27] - [7.28]. Each proposed reform is problematic and integration across the reforms is even more problematic. The current state of work based learning is clearly one the research team feels is in need of reform rather than available as a source of solutions. As well as providing assurances of competence at the beginning and during a professional career, and developing professional attributes, work based learning is hopefully going to alleviate the problems of social mobility posed by problems of access to the profession [6.51] - [6.54].The Report recognises the infeasibility of a grand reform in such complex matters and recommends setting up a Legal Education Council to try and inform continuous regulatory reforms at recommendation 25.

${ }^{2}$ LETR Report p. ix: "enhance consistency of education and training through a more robust system of learning outcomes and standards, and increased standardisation of assessment", [4.106], [4.122], and

Recommendations $1-5$.

${ }^{3}$ See: LETR Report [4.94] [4.110], [4.134], and [4.139] which identify problems with outcomes in this area; but these problems seem to be forgotten at [4.140]. Also, see below in particular the text between notes 11 and 16 for an exploration of this problem.
} 
The support found by the research team for a greater emphasis on values and ethics is impressive and welcome. To summarise:

\begin{abstract}
"Ethics, values and professionalism ... was rated the most important knowledge area in the LETR online survey, a result which echoed the demand for a greater emphasis on professional ethics and conduct across the qualitative data and stakeholder responses to Discussion papers ... A majority of respondents took the view that ethics and professionalism need to be developed throughout the continuum of education and training." 4
\end{abstract}

In short, although there already exists some ethical and value informed education and training it is felt more would be a good thing. At undergraduate level (and GDL) expanding the foundation subjects would cut into time available and limit academic freedom. Although there was some support for professionalism or ethics as a foundation subject it was a minority who favoured this. ${ }^{5}$ The proposal for the undergraduate stage of legal education was:
"Hence, it is proposed that the QLD/GDL should include outcomes that advance an awareness and understanding of the values embedded in law, legal processes and solutions, and the role of lawyers in advancing those values. Further ... that some understanding of underlying legal values should be incorporated in the education and training of any authorised person." 6

To sum up:

"The perceived centrality of professionalism and ethics to practice across the regulated workforce is one of clearest conclusions to be drawn from the LETR research." 7

A lot of people see the teaching of ethics as a known and potentially effective solution to a lot of problems. The research team agrees and recommends, inter alia, that the undergraduate stage of legal education should direct some resources in this direction. However, there are no recommendations as to content, or delivery, and expressly no recommendation for "professional conduct" to become a foundation subject. ${ }^{8}$

The final recommendations on ethics and values are 6 and 7:

\footnotetext{
${ }^{4}$ LETR Report [4.65] - [4.67]

${ }^{5}$ Indeed, there is some evidence that teaching ethics as a discrete subject can be ineffective, see: Ernest T. Pascarella and Patrick T. Terenzini, How College Affects Students: A Third Decade of Research: 2 (2005) John Wiley \& Sons Inc, San Francisco, Ca, at p. 355: "Ethics courses. Another purposeful intervention designed to facilitate growth in principled moral reasoning is a course focussed on ethics. This approach has been particularly visible in undergraduate business curricula ... The weight of evidence from these studies is somewhat equivocal .... We suspect that the mixed findings for this body of evidence reflect to some extent the fact that ethics interventions in the various studies differed substantially in their content, emphasis, and implementation. On balance, across all studies the effect on principled moral reasoning of exposure to either ethics courses or interventions is probably positive, though quite modest in magnitude."

${ }^{6}$ LETR Report [4.104].

${ }^{7}$ LETR Report [7.10].

${ }^{8}$ LETR Report [7.89].
} 


\begin{abstract}
"Recommendation 6
LSET [Legal Services Education and Training] schemes should include appropriate learning outcomes in respect of professional ethics, legal research and the demonstration of written and oral communication skills.

Recommendation 7

The learning outcomes at initial stages of LSET should include reference (as appropriate to the individual practitioner's role) to an understanding of the relationship between morality and law, the values underpinning the legal system, and the role of lawyers in relation to those values."
\end{abstract}

Both the revelation of the degree of support for greater emphasis on values and ethics in legal education and training, and the clear indication that it is a matter for all stages of legal education, are to be welcomed. However, a full set of three cheers must be denied, because of the understandable but potentially treacherous issue of perspective. The viewpoint of the research team was not the same as the viewpoint of the academic institution considering what might be appropriate undergraduate learning outcomes.

\title{
How the perspective of the research team obscures educational implications
}

This LETR Report is welcome to those who wish to see more attention given to values and ethics in legal education generally and the academic stage in particular. Less welcome are two features of the treatment of ethics and values in the Report.

First, ethics teaching risks becoming a vehicle for social engineering - it risks being put forward as an instrument for regulatory aims. It cannot be a vehicle for delivering the full commitment to client of the traditional professional for the price of the lowest cost competitive supplier whilst maintaining the values of justice and delivering to the financial investor the required $15 \%$ return on capital. In the words of Kurt Lewin:

"It seems to be easier for society to change education than for education to change society." 9

There is a tendency for utopian hopes to be pinned upon educational initiatives, but neither education nor regulation can square the circle of inconsistent policy imperatives. ${ }^{10}$ Educators must be careful not to impose unrealistic demands upon our students, and our

\footnotetext{
${ }^{9}$ Kurt Lewin, Some Social-Psychological Differences Between the United States and Germany (1936) in Resolving Social Conflicts and Field Theory in Social Science (1997) Washington, DC: American Psychological Association, (2010) electronic edition.

${ }^{10}$ The problem is not unique to legal services or the UK, see: David F. Labaree, Someone Has to Fail: The zerosum game of public schooling (2010) Harvard University Press, Cambridge, Mass at loc 10: "We Americans have long pinned our hopes on education. It's the main way we try to express our ideals and solve our problems. ... So we assign these social missions to schools, and educators gamely agree to carry them out. When the school system inevitably fails to produce the desired results, we ask reformers to fix it. ... The system never seems to work the way we want it to, but we never give up hope ... just keep tinkering."
} 
educational institutions. Alignment of the educational experience with the best interests of the learner and not the perceived needs of the legal services market is crucial. We can help the profession and the regulators, but we cannot do it by subsuming the interests of the students to the market. That would be unethical for educators and a very unstable foundation for the teaching and learning of ethics and professional values.

Second, the Report notes ${ }^{11}$ but loses sight of the peculiar nature of ethics education as being more than cognitive or skills based. Ethics is primarily about behaviour rather than argumentation. The theory of ethics is not ethics. Indeed there is a risk that teaching theory of ethics enables the unethical learner to develop powers of rationalisation that facilitate unethical behaviour:
"I remember one CEO who told me that while interviewing a recent MBA graduate for a job, he asked the man whether he had taken a course in business ethics. When the interviewee answered yes, the CEO asked him what he had learned. The job candidate explained that he had learned about all the models of ethical analysis - deontology, virtue ethics, consequentialism, and so on - and that whenever he encountered a conflict, he could decide what he wanted to do and then select the model of ethical reasoning that would best support his choice." ${ }^{12}$

If one reviews the recommendations and proposal quoted above the LETR Report seems to have reverted to a cognitive approach to ethics demanding: "outcomes that advance an awareness and understanding". This is in part because the Report deals with "integration" as a separate aspect of educational endeavour to ethics and values. ${ }^{13}$ However, the best contender for an educational intervention that is integrative in the required sense is an ethical or moral one concerned with both the values of the individual and those of the system. Indeed, this integrative role of ethics and considerations of values in legal education was emphasised by the recent Carnegie Report which developed the idea of three apprenticeships reflecting three dimensions of professional work: the intellectual or cognitive (thinking); expert practice (performing); identity (behaving). The Report expanded upon the general nature and content of the third apprenticeship:

\footnotetext{
"The third apprenticeship, which we call the apprenticeship of identity and purpose, introduces students to the purposes and attitudes that are guided by the values for which the professional community is responsible ... it also shares aspects of liberal education in attempting to provide a wide, ethically sensitive perspective ... the essential goal ... is to teach the skills and inclinations, along with the ethical standards,
}

\footnotetext{
${ }^{11}$ LETR Report at: [4.65], [4.83] - [4.86],

12 Mary Gentile, Giving Voice to Values: How to speak your mind when you know what's right (2010) Yale University Press, New Haven, electronic edition, at loc. 103.

${ }^{13}$ LETR Report [4.76], Table 4.3 - five of the six classes of "competencies" have ethical components or would potentially be developed through ethical education, context is the odd one out.
} 
social roles, and responsibilities ... it is the ethical-social apprenticeship through which the student's professional self can be ... explored and developed." ${ }^{14}$

One purpose of this third apprenticeship is to carry out the integration of the intellectual and practical and identity aspects of legal education:

"Because it directly addresses professional life in all its dimensions, the apprenticeship of identity and purpose is the natural site for integration." ${ }^{15}$

In short one of the most exciting aspects of teaching ethics or making values central in legal education is the impact it can have upon the identity and sense of self being developed by the student learner. But in this the cognitive aspect of ethical teaching is not primary, it serves the greater purpose. It is from such an understanding of ethics as being about behaviour not words that the legal educator can most effectively serve the felt needs of the legal practitioners and the legal regulators. This aspect of ethical education causes one point of friction with outcomes based assessment practice: the possibility of an authentic metric seems deeply problematic.

The issue is whether future behaviour will be affected by ethical education and training. The answer is unknowable until the circumstances that test the question arise. In this area therefore, the better approach is sometimes to demand experience with the processes involved in ethical education: such as dilemma argument; or exposure to powerful role models; or opportunities to engage in service activities; or exposure to material on diversity that counteracts common negative stereo-types. One can assess for engagement (presence and completion of tasks), and understanding (explaining the theory or substantive content of taught materials and application of the same), and even perceptual sensitivity (can students see issues raised by representing a buyer and seller in the same transaction). In an experiential setting, such as a clinic, the reflective practice method of teaching and assessment offers scope for a somewhat more realistic assessment of such qualities. But even this is a poor proxy for the real issue - how the student will act in the future in an unsupervised environment under the pressures of life. Essentially a key aim of ethical education that cannot be assessed is the internalisation of ethical standards into the selfidentity of the student, and it is not only futile to try and assess this outcome directly but also intrusive. Educationally it fails to respect student autonomy sufficiently, and professionally it substitutes a passive compliance for a critical and sincere internalisation of professional ethics and identity.

\footnotetext{
${ }^{14}$ William M, Sullivan, Anne Colby, Judith Welch Wegner, Lloyd Bond, Lee S. Shulman Educating Lawyers: Preparation for the Profession of Law (2007) Jossey-Bass: San Francisco, CA, at p. 28, loc. 430-439.

${ }^{15}$ Ibid. at p. 196, loc. 2773 . See also at p. 14, loc. 263 : "The third element of the framework - professional identity - joins the first two elements and is, we believe, the catalyst of an integrated legal education. The third element of our framework for legal education, which is sometimes described as professionalism, social responsibility, or ethics, draws to the foreground the purposes of the profession and formation of the identity of lawyers guided by those purposes."
} 
Undergraduate students value highly the personal development they experience at University. The SOMUL project termed this the "identity-projects" of the students. ${ }^{16}$ This usage echoes the terminology of Giddens who argued that modernity imposes a project on individuals, because ascribed roles and identities are inadequate outside of traditional social orders, modern life does not produce unchanging cycles of life and ascribed role identity. Who we are becomes a problem we have to deal with, self-awareness and social instability means that:

"Self-identity today is a reflexive achievement. The narrative of self-identity has to be shaped, altered and reflexively sustained in relation to rapidly changing circumstance of social life." 17

Identity is not singular, we can have numerous identities that play a role in our life narrative. ${ }^{18}$ One potentially important identity is professional, and as Peter Birks remarked:

"A law school fails in its teaching if it does not give its graduates the opportunity to make a moral commitment to their subject and through their subject to the public good." 19

In other words undergraduate students need to decide who they are, they are aware of this process of becoming, and consider University to be valuable because it is a time and place they can use to pursue this need. In the words of the report on the SOMUL project:

"not everyone experiences major personal change as a result of going to university. But most do." 20

This need generates a duty in legal educators to try and support the students in this process of constructing identities for themselves. To be clear: the students will act in any event, and we have no warrant to try to impose an identity upon the students; hence, the great care needed to identify the correct perspective of the educator as opposed to the regulator. However, we can facilitate without imposing, and to do nothing in the name of neutrality is actually a failure on our part:

"to give people a conceptual vocabulary is to influence them; but to deprive them of it is to cripple them, not to empower them." 21

\footnotetext{
${ }^{16}$ John Brennan, Robert Edmunds, Muir Houston, David Jary, Yann Lebeau, Michael Osborne and John T.E. Richardson, Improving What is Learned at University: An exploration of the social and organisational diversity of university education (2010) Abingdon: Routledge

${ }^{17}$ Anthony Giddens, Modernity and Self-Identity: Self and Society in the Late Modern Age (1991) Polity, Cambridge, at p. 215.

${ }^{18}$ Amartya Sen, Identity \& Violence: The Illusion of Destiny (2006) Penguin, London.

19 Peter Birks in Peter Birks (ed) (1996) What Are Law Schools For? Oxford University Press, Oxford at xiv:

${ }^{20}$ Op. Cit n. 13 at pp.155-156.

${ }^{21}$ Kwame Anthony Appiah (2005) The Ethics of Identity, Princeton University Press, Princeton, NJ at loc. 1067.
} 
One identity we should offer is surely that of a legal professional, we should facilitate and make meaningful the possibility of law students making "a moral commitment to their subject". We can do this through giving the students a conceptual vocabulary, and it is a conceptual vocabulary drawn from ethics and value discourse. However, a conceptual vocabulary is not enough, and it would be better if we also helped them develop awareness, the ability to reason critically and validly, courage, and effective strategies for action in accordance with their beliefs. Such learning opportunities can help them to integrate their experiences, and to make a moral commitment, and to forge an integrated professional identity, if they so choose.

\section{A very summary account of ethical education and another caution around assessment}

There is more than one model of the causative factors that underlie ethical action, ${ }^{22}$ but one that has proved robust and been influential in professional education was developed by Rest. In his own words:

"My view of the major determinants of moral behaviour (the Four Component Model) came to be formulated while I was doing a general review of the morality literature ... the Four Component Model starts with the question, 'What must we suppose happens psychologically in order for moral behaviour to take place?' We wind up with at least four distinct processes." 23

The components are: sensitivity - awareness of an ethical issue raised by a situation; judgment - the ability to reason correctly about the nature of the ethical issues and to identify what an ethical response would be; motivation - wanting to act ethically having decided what that would entail; character - the ability to act ethically. The first is about perception, which may require sensitivity or empathy, it often requires emotional or social intelligence. The second is about cognition and reasoning, there is an influential theory, associated with Kohlberg, that moral reasoning is developmental in nature, and that undeveloped people simply cannot understand certain types of ethical argument. The third is about what one cares about, what one values, which may involve an internalisation of values undertaken as part of an identity project. The final component is about courage in the face of possible disapproval or opposition and feelings of efficacy. All four of these components need to be present for effective ethical action.

The four component model is useful for educators because it identifies attributes of the individual learner that might benefit from informed educational practice. It breaks down the otherwise intractable problem of inculcating ethical character into tractable steps. It also brings home the other reason why outcome based educational practice can be dangerous in

\footnotetext{
${ }^{22}$ For a model that seeks to explore situational rather than only individualistic factors see: Richard Moorhead, Victoria Hinchly, Christine Parker, David Kershaw, and Soren Holm, Designing Ethics Indicators for Legal Services Provision (2012).

23 James R. Rest and Darcia Narvaez, Moral Development in the Profession: Psychology and Applied Ethics (1994) Laurence Erlbaum Associates Inc, Hillsdale, NJ at p. 22.
} 
ethical education. As well as the artificiality of proxies for ethical character the nature of the values adopted (component two and three) is subject to legitimate and radical difference of opinion. To try and assess in this sphere (with allowance for less freedom of legitimate opinion in the sphere of ethical conduct governed by professional codes) becomes a politically divisive conformity test.

It has been shown that one can cheat the Defining Issues Test for moral reasoning, ${ }^{24}$ and use of the test in education and training would have little effect other than destroying the usefulness of the test. However, even if such a form of assessment were practicable the Kohlberg stages have been criticised because they allegedly reflect political preferences. ${ }^{25}$ Unquestionably at the undergraduate stage of legal education any assessment regime must respect value differences expressed by students. We must facilitate the identity projects of students rather than trying to co-opt them for the purposes of the profession, or regulators, or even the legal system. We must put our confidence in the inherent persuasiveness of the values we espouse and resist the temptation to try and impose them through assessment. In the words of Derek Bok:
"It is not the place of faculty members to prescribe what undergraduates ought to consider virtuous. But surely faculties should do whatever they can to prepare their students to arrive at thoughtful judgments of their own" 26

Although we might also hope to help our students to become sensitive to ethical issues in daily life, and effective moral actors, the emphasis Bok places on student autonomy seems correct. In the undergraduate context the ethics of professional service are ones we should offer up for consideration, critical reflection, and adoption.

\section{Conclusions}

Recommendation 10 of the LETR Report calls for a review of the undergraduate qualifying law degree and Graduate Diploma in Law and Recommendation 11 states:

"There should be a distinct assessment of legal research, writing and critical thinking skills at level 5 or above in the Qualifying Law Degree and in the Graduate Diploma in Law ..."

\footnotetext{
${ }^{24}$ See: Nicholas Emler and Bernadette Malone, The Relationship Between Moral Reasoning and Political Orientation (1983) 45 Journal of Personality and Social Psychology 1073; Nicholas Emler and Emma PalmerCanton, Politics, moral reasoning and the Defining Interest Test: A reply to Barnett et al (1995) (1998) 37 British Journal of Social Psychology 457. These studies suggest that even a conscientious annual redrafting of the actual questions asked in the DIT would not be effective. The problem is the student is undertaking the test with a purpose (passing well) that is not conducive to the test functioning properly.

${ }^{25}$ See in addition to the articles cited above: Carol Gilligan, In a Different Voice: Psychological Theory and Women's Development (1990) Harvard University Press; Steven Hartwell, Promoting Moral Development Through Experiential Teaching (1995) 1 Clinical Law Review 505.

${ }^{26}$ Derek C. Bok (2006) Our Underachieving Colleges: A Candid Look at How Much Students Learn and Why they Should be Learning More, Princeton University Press, at p. 150.
} 
This recommendation can be met thorough ethically informed teaching. At Nottingham Law School our final year Critical Legal Thinking module combines an ethical and value informed curriculum with assessment of the rigour and soundness of students' critical thinking, research skills, and writing skills. ${ }^{27}$ One way of generating an appropriate set of learning outcomes can be through such courses. More generally there is a need to identify what a review of the QLD informed by the LETR Report offers, and to chart some predictable hazards to the successful navigation of any such review.

The emphasis on values and ethics and professionalism is an opportunity. As already noted recommendations 6 and 7 call for learning outcomes that encompass ethics and values and professionalism. Ethical reasoning is pre-eminently critical thinking, and links to recommendation 11. Academic providers should regard these recommendations in a positive light because they can be used to help students in their identity projects. Thus, the argument is that there is a concurrent interest in academic ethics and professional ethics in facilitating and supporting the identity-project of each of our students.

At the same time there is a clear risk or hazard in giving greater emphasis to values and taking an interest in the identity-projects of students. We must be careful of what we attempt to assess, and accept non-assessable outcomes probably best prescribed (if at all) by the observable levels of provision and engagement; and to deny ourselves the power to determine which internalised values are the right ones for students to adopt.

Ethics and values can be taught anywhere in a curriculum: in jurisprudence; or in clinical legal education; or in traditional foundation subjects; or optional modules; or specialist ethics modules; or in keystone research dissertations. Moral reasoning seems to be enhanced by discussion of dilemmas and elaboration of the circumstances of particular cases. These features of casuistic reasoning are familiar from case law. Indeed value discourse is naturally adaptable to signature pedagogies of legal education. It would seem that a values approach would be welcome to legal academics, as it offers a way to enrich the very pedagogies we have developed in practice over time. Peter Birks identified one source of hesitation:

"This is difficult because of the proximity of propaganda and indoctrination." ${ }^{28}$

This concern has been addressed above. A concern that ethical education will be no more than teaching the codes of professional conduct has also been implicitly rejected above. ${ }^{29}$ In short that would not be appropriate at undergraduate levels.

\footnotetext{
${ }^{27}$ This potential for combining value discourse with jurisprudence was also noted in : Seow Hon Tan, Teaching Legal Ideals Through Jurisprudence (2009) 43 The Law Teacher 14.

${ }^{28}$ Peter Birks in Peter Birks (ed) (1996) What Are Law Schools For? Oxford University Press, Oxford at xiv.

${ }^{29}$ For an incisive critical account of such a model see: William H. Simon, The Trouble With Legal Ethics (1991)

41 Journal of Legal Education 65.
} 
There seems to be another cause for concern: that values or ethics are soft and not capable of rigorous analytical treatment. Possibly some legal academics believe that the law has to be freed from the subjective and contested field of values in order to be teachable as law. Philippa Foot said:

"[Q] But people think that sometimes there is a difficulty reconciling morality with rationality.

[PF]They do, but I believe it is a mistake to think you've got an independent idea of rationality; that there is one idea of rationality and one idea of morality and somehow you have to reconcile them. They're not separate. From the beginning, if you like, morality leads rationality and not the other way round." 30

Reflection and teaching about values and ethics and professional practice are not a distraction from the business of legal education: rather, they are its most effective vehicle. In the words of the Carnegie Report:

"A more effective way to teach is to keep the analytical and the moral, the procedural and the substantive in dialogue throughout the process of learning the law." ${ }^{31}$

Hopefully the forthcoming review of the law degree will enable this potential to be realised and put into practice across the higher education sector.

30 Philippa Foot interview in 2001 published in 2013 Sept/Oct issue of Philosophy Now.

${ }^{31}$ Op. Cit n. 11 at p. 142 Loc. 2021 